\title{
О ФОРМИРОВАНИИ И СТАНОВЛЕНИИ СФЕРЫ КУЛЬТУРЫ В ПУРОВСКОМ РАЙОНЕ ЯМАЛО-НЕНЕЦКОГО АВТОНОМНОГО ОКРУГА В ПЕРИОД С 1920-Х ПО 1950-Е ГОДЫ
}

\author{
Храмова Наталья Евгеньевна \\ заместитель директора по научной работе \\ МБУК «Пуровский районный \\ историко-краеведческий музей»
}

\begin{abstract}
Аннотация: В статье использованы архивные документы музейного фонда «Пуровский районный историко-краеведческий музей». На основе источников сделаны выводы о становлении и развитии сферы культуры в Пуровском районе в 30-50-е годы XX века.

Ключевые слова: Сфера культуры, просвещение, общественнополитическая и культурная жизнь, красные чумы.

\section{ABOUT THE FORMATION AND FORMATION OF THE SPHERE OF CULTURE IN THE PUROVSKY DISTRICT OF THE YAMALO-NENETS AUTONOMOUS OKRUG IN THE PERIOD FROM THE 1920S TO THE 1950S}

\section{Khramova Natalia Evgenievna}

\begin{abstract}
The article uses archival documents of the museum fund «Purovsky District Museum of Local Lore». Based on the sources, conclusions are drawn about the formation and development of the sphere of culture in the Purovsky district in the 30-50-ies of the twentieth century.

Key words: Sphere of culture, education, socio-political and cultural life, red plague.

Относительно утверждений о становлении культурной сферы в обозначенный период источники разноречивы. Одни [1, c. 100] указывают на начало 20-х годов XX в., обозначая именно эти годы точкой отсчёта в «подлинной работе по культурному просвещению Севера», другие же [2, с. 20], нам говорят о том, что советизация, развернувшаяся в 20-е годы и


продолжавшаяся до середины 30-х годов XX в., сопровождалась волнениями, активными сопротивлениями, выливавшимися в столкновения и стихийные проявления недовольства среди коренного населения тундры относительно новой власти в 1932-1933гг. Протесты повсеместно приобретали разные формы на территории нынешнего ЯНАО, что не даёт предпосылок к началу становления сферы культуры в данный период.

Ещё в 1935 г. более 500 хозяйств отказывались выполнять требования советской власти [2, с. 105]. Многие семьи становились бесправными, т.е. «лишенцами», становясь в ряды «шаманов», «держателей батраков», «кулаков». Так в Пуровском районе таких насчитывалось 115 человек из «немногим более 1000 человек» всего населения района [3, с. 5].

Выезд в тундру Красных чумов, разъяснительная работа среди коренного населения результата не давали. Продолжали действовать группировки, называемые «кулацко-шаманскими». Вначале 30-х годов было разграблено несколько факторий, убиты и подвержены пыткам уполномоченные лица и заведующие факториями. Сопротивление ненцев мероприятиям советской власти было сломлено лишь к 1934 году, и в дальнейшем активных форм не приобретало [2, с. 108]. Окончательно на Ямале ликвидация «классово-чуждых элементов» была завершена в ходе репрессий 1937-1938гг.

В связи с малоизученностью быта малых коренных народов севера и их степени просвещённости в принятом в 1926 г. Совнаркомом РСФСР постановлении «О просвещении национальных меньшинств» не были учтены национальные традиции, обычаи, в укладе и образе жизни коренного населения. Несколько раньше, в 1925г., постановлением ВЦИК и СНК РСФСР создаются местные комитеты Севера, в деятельности которых культпросвет работа должна была стоять на первом месте, но на деле осуществиться ей в полном объёме на тот момент возможности не представлялось.

Основными направлениями деятельности органов, ответственных за культурное просвещение населения тундры стали: создание школьной сети, включая школы-интернаты, кочующие школы, организация культурных баз, которые должны стать центром, как хозяйственной, так и культурнопросветительской деятельности среди коренного населении, ликвидация безграмотности среди кочевников и приобщение их к основным достижениям цивилизации, были первоочередными задачами. И в связи с таким положением, именно школы становятся центрами культурно-просветительской работы, 
удовлетворяющими элементарные культурные запросы населения. Но всё ещё остро стоял вопрос языка обучения [2, с. 21]:

Со второй половины 20-х годов центры культурной работы на территории ЯНАО представляют культбазы - комплексные учреждения, кроме школыинтерната, в состав которой входили: больница, фельдшерский пункт, 30опункты, избы-читальни, Красные чумы. Помимо этого, задачи культурного развития были возложены руководством партии на библиотеки, народные дома, клубы, музей, периодическую печать и радио.

Лишь к середине 20-х годов на территории нынешнего ЯНАО стали устанавливать радио-телеграфные станции, но подключены были только отдельные посёлки.

По переписи 1927 года грамотность коренного населения составляла в среднем 0,4\%, в 1931 году - 1,4\%, в 1940 - 10\%. Налицо культурнопросветительская работа с коренными жителями, медленная, но верная. Но такая статистика отчасти даёт представление об уровне потребности в духовной пище и культурных запросах коренного населения, когда насущными остаются нерешённые вопросы устройства быта и элементарной санитарии.

К 1936 году в Округе насчитывалось: библиотек - 17; Красных чумов - 5; изб-читален -10; красных уголков - 63; Домов ненца - 4. Только в Салехарде в 1935 году действует звуковое кино. Красные чумы действуют с 1932 года и являются основной формой культурного просвещения среди ненецкого населения. Основными формами работы являются: беседы, лекции, вербовка детей в школы, ликбез среди взрослых и сбор фольклора. Но работа избчитален и красных чумов на тот период окружным руководством оценивается неудовлетворительно. Причины видятся такими: слабое руководство со стороны ВКП(б), профсоюзов, органов народного образования, слабая материальная база культбаз, отсутствие финансирования, отсутствие национальных кадров для всех типов культурных учреждений, низкая квалификация имеющихся кадров. Также затрудняет работу наличие многообразных наречий и отсутствие письменности к 1925 году.

Вначале 1932 года по решению Ямало-Ненецкого Окрисполкома создаётся Оргбюро Пуровского района во главе с Г.И. Оносовым. Лишь в конце апреля 1932 года сформирована Пуровская экспедиция, но направляется она на место организации района только в июле 1932 года [3, с. 1-4]. И только в конце декабря 1932 года экспедиция достигает развилки рек Айваседо-Пур и ПякуПур, где и было предусмотрено строительство района. Следовательно, о 
развитии культурной сферы с 20 -х по 1932-1933 годы говорить нецелесообразно ввиду отсутствия административной единицы Пуровский район, как таковой.

Приведённые ниже выдержки из воспоминаний основателей района и старожил помогут воссоздать общую картину интересующего нас периода и прольют свет на положение вещей в эти суровые годы.

«...В один из мартовских дней в 1933 году состоялся съезд, на который прибыло 40-50 делегатов, к сожалению никто из них не мог говорить порусски...Наблюдались саботажи и сопротивления из-за недобросовестного распределения норм по заготовке пушнины и расчётов с коренным населением...

Но для подкрепления политики партии РСФСР ещё в 1933г. не было материальной базы, не было ни радио, ни кино, и даже не была налажена торговля...Главным являлось снабжение, а в то время фактории (лавки) были только в Ивай-Сале, Тарко-Сале, Харампуре, но все они находились в подчинении Тазовской конторы «Уралпушнины»...

Учтено было немногим более 1000 человек (населения), из них знали русский лишь несколько... Мы старались, чтобы у каждого жителя в чуме была железная печка, но привыкали они к ней очень медленно, предпочитая лист железа посреди чума, костёр и вечный дым, разъедающий глаза... Бедность в то время была уделом многих...Здесь (в Пуровском районе) было целевое снабжение, т.е. продукты выдавались только против сданной пушнины или рыбы по строго определённым нормам.

Если в настоящее время транспорт и связь не являются проблемой с этим отдалённым регионом, то в то время мы имели возможность получать почту 1 2 раза в год. Радиосвязь с районом (Пуровским) была установлена лишь через 2 года после его организации (т.е. в 1934-1935 гг.) [3, с. 6]».

1935 год. «...Недостаточно развёрнута культурно-просветительская работа и среди взрослого населения, как русского, так и туземного. В доказательство этого можно привести ряд фактов. Например, на фактории Харам-Пюр (пунктуация и орфография автора сохранены), где зимой 19351936 гг. сосредоточено около 20 человек русского населения не выписывается ни одного экземпляра газет и журналов, нет ни одного комплекта шахмат, как и других игр, нет библиотечки, нет радиоприёмника. Как будут проводить свой досуг зимовщики фактории для нас остаётся загадкой... 
В самом районном центре (Тарко-Сале), несмотря на наличие радиостанции, во всём посёлке, кроме самой радиостанции, куда вход посторонним запрещён, нет ни одного громкоговорителя, никто из живущих в посёлке не слушает радиопередачи. Районный центр также не имеет библиотеки и красного уголка, где можно было бы прочесть газету или журнал. Кружки полит-учёбы в некоторых населённых пунктах района (Тарко-Сале, Ивай-Сале) хотя и организованы, но занятия в них ведутся от случая к случаю. Культурно-просветительская работа с коренным населением стоит на более низком уровне. В районе нет ни одного Красного чума, как не было их и в прошлые годы. Национальные советы, кочующие с туземным населением, конечно, проводят среди последнего беседы по различным общественнополитическим вопросам, но этого явно недостаточно, нужна планомерная работа, обеспеченная соответствующими силами и средствами, нужны Красные чумы...»[4, с. 2].

В 1937 году продолжается вербовка рабочих по деревням и городам Омской области. Изначально все отправлялись на баржах по Оби до Обдорска (Салехард), затем по реке Пур до Тарко-Сале. Приезжее население строили землянки, селились по 2 семьи. Завербованных рабочих распределяли по факториям по всей территории Пуровского района. В источниках нет сохранившихся данных о существовании клуба в Тарко-Сале, кроме воспоминаний старожил: «...на берегу была школа-домик, потом выстроили другую, в нём же был интернат, с другой стороны клуб со сценой и небольшим залом, где танцевали, библиотека...»[5, с. 2].

1941 год. «1 января открыта в Тарко-Сале первая типография газеты «Едай Ил» - с нен. «Новая жизнь». В 1942 году закрывается и открывается вновь в 1944 году.

«...В 1943-м отец (Реховский Пётр Герасимович 1900г.р.) вернулся с фронта... его часто просили поиграть в клубе на самодельной гармони, молодёжи хотелось потанцевать. Вечера были платные, деньги шли в фонд обороны. Его дети сидели, слушали, остальных детей в клуб не пускали. Обувь была у кого калоши, у кого брезентовые туфли. Смотрели не озвученные фильмы, в основном про войну...» [5, с. 1].

«..На 1941 - 1944 гг. структура Пуровского района состоит из 3 сельсоветов - Тарко-Салинского, Верхне-Пуровского и Нижне-Пуровского, 6ти колхозов, и газета отражает главные события, происходящие в районе, в округе, стране... Организацией субботников занимались Райком партии, 
Райком комсомола по инициативе РК ВЛКСМ (Всесоюзный Ленинский коммунистический союз молодёжи). После окончания войны субботники организовывались по выходным дням, заработанные деньги перечислялись на реализацию молодёжных мероприятий...» [7, с. 2].

1941 - 1945 гг. «...Большое внимание уделяется массовой политической работе среди населения. На это были направлены представители районных партийной и комсомольской организаций. В период пушзаготовок и весеннелетней пушнины 1944 года 75\% партийно-комсомольского и советского актива находилось на местах промыслов. Для работы с коренным населением тундры было выделено 18 агитаторов, 7 коммунистов и 5 комсомольцев. Большую работу провели такие товарищи как А Вэлла Ани (колхоз им. Сталина), Казымкин Манчели (к-з «Едай Яле»), Тер Арся (к-з «Красный рыбак»), Вора Пилюта (к-з «Едай Ил») и др.

В 1944 году работниками культуры района проведено для населения 263 беседы, 134 читки газет, 39 докладов, 30 постановок, 87 вечеров, 13 вечеров вопросов и ответов, 34 собрания, проведено 30 занятий в школах ликбеза, с охватом учащихся 334 человека.

Особенно хорошо была поставлена работа в 1945 году Халесовинского Красного чума (зав. Воронкова), она руководила коллективом. В работе Красного чума не было оторванности от выполнения хозяйственных и политических задач, стоящих перед колхозом «Едай Яле». В течение всего года коллектив работников Красного чума находился в гуще колхозников и проводил с ними систематическую массово-политическую работу. Красный чум являлся центром массово-политической работы в Халесовинской тундре...» [8, с. 1].

1951 год. Оценить обстановку в сфере культуры представляется возможным по воспоминаниям старожил: «...Школа была на берегу реки, через дорогу была столовая. Был клуб «Маяк», стоял по ул. Республики 13. В посёлке электричество появилось в 1956-1957 гг...» [7, с. 1].

Весь собранный материал не даёт чёткой картины развития сферы культуры в Пуровском районе, но обрисованная обстановка в общественнополитической жизни даёт нам основание считать, что основным центром как массово-политической так и культурной жизни района, начиная с его основания, т.е. с 1932 года, являлись Красные чумы. Их работа активизировалась лишь к концу 30 -х годов XX в. Культурная жизнь не могла идти в отрыве от политики, проводимой советским государством, учитывая 
задачи, поставленные коммунистической партией и внедряемую ей идеологию социалистического строительства.

В 40-е годы XX в. в населённых пунктах Пуровского района появляются стационарные учреждения культуры - клубы. Зачастую помещения сельсоветов выполняют функции культурных центров, являясь средоточием всех форм работы с населением.

Есть все основания считать, что культурная сфера как институт начала оформляться и формироваться лишь с освоения месторождений, т.е. с середины 1960-х годов, с естественным привлечением приезжего населения, со строительством всевозможных коммуникаций, что позволило наладить связь с «большой землёй», что в свою очередь стало базой для основания нового культурного пласта. Вместе с тем, культурная жизнь района имела место быть в общеизвестных формах, сообразно с особенным жизненным укладом народов Севера, их мировоззрением, в каждой отдельно взятой семье или доме, чему способствовали большие творческие способности малочисленных коренных народов, как отмечали исследователи Севера ещё начала века [9, с. 3].

\section{Список литературы}

1. Материалы научно-практической конференции, посвящённой 90летию Ямало-Ненецкого краеведческого музея «Музей: вчера, сегодня. Завтра». - 1998г. - Статья «Распространение образования и культурное просвещение на Ямале в 20-е - 30-е гг. ХХ в.»- С. 100-108.

2. Ежегодник Тюменского областного краеведческого музея 1996г. Статья В.П.Петрова «Волнения ненцев на Ямале в 1932-1934 годах» - С. 20-108.

3. М. Саргин - воспоминания. - «Пур - река своенравная». - Фонды ПРИКМ - ОФ $5094-$ С.1-8.

4. Фонды ПРИКМ - КП 13919 «Ксерокопия. «О развитии культурнообразовательной жизни в Пуровском районе». Из отчётов областной комиссии C. 1-3.

5. Воспоминания Реховской-Сторожко Раисы Петровны 1930 г.р. Фонды ПРИКМ - НВф 4836/1-3- С.1-3.

6. Воспоминания Реховской-Мазур Галины Петровны 1937г.р. -Фонды ПРИКМ - НВф 4841/1 - С.1-3.

7. Воспоминания Сторожко Р.П. о работе в типографии газеты «Едай Ил» (1941-1960 гг.). Фонды ПРИКМ - ОФ - 2396 - С.1-4. 
8. Записи отчётов за 1941 -1945г. Фонды ПРИКМ - КП - 12311/1-12 C.1-12.

9. Житков Б. - Полуостров Ямал. - СПб. - 1913 - С.3-5.

(C) Н.Е. Храмова, 2022 